\title{
XXIII. On a syphon hydrometer, and its use in finding the temperature of water at the greatest density
}

\section{Mr. Henry Meikle}

To cite this article: Mr. Henry Meikle (1826) XXIII. On a syphon hydrometer, and its use in finding the temperature of water at the greatest density, Philosophical Magazine Series 1 , 68:341, 166-168, DOI: 10.1080/14786442608674104

To link to this article: http://dx.doi.org/10.1080/14786442608674104

册 Published online: 10 Aug 2009.

Submit your article to this journal $\pi$

ЏII Article views: 2

Q View related articles $₫$ 


\section{[ 166 ]}

XXIII. On a Syphon Hydrometer, and its $U$ se in finding the Temperature of Water at the greatest Density. By $M x$. Henry Meikle*.

THIS hydrometer consists of a glass tube, open at both ends, and bent into a sort of double syphon, having four parallel legs; so that the open ends are pointed in the same direction, or upwards, as in the annexed figure.

The manner of using it is very simple: Let one of the ends be stopped with the finger or with a cork, and water be poured into the other. This fluid will only rise a small way into the second leg, because of the included air. Next stop the other orifice, and open the one first closed; and having poured into the latter the liquid whose specific gravity is to be tried, open the top of the water-tube; then the instrument being held upright, the two liquids will arrange themselves so as to press equally on the included air. Now this pressure will be measured by the difference in the heights of the two columns of either liquid multiplied by its specific gravity. So that by dividing the difference of the two columns of water by the difference of those of the other liquid, we obtain the specific gravity of the latter; that of water being unity + .

The difference between the columns, which is the effective column, may be measured by applying any scale of small equal parts; or the glass might for greater safety be attached to a graduated board or plate, and this furnished with verniers, \&c. Some little attention must be paid to the quantities of the liquids employed, for the longer the columns are the result will be the more certain; but no great nicety is required as to the precise quantity of either liquid. It is plain that the expansion of the glass or its capillary action have nothing to do with the result. Nor can the expansion of the scale have any influence; because the ratio of the columns is not altered thereby. Only if the temperature differ from the standard, as from $40^{\circ}$

* Communicated by the Author.

+ The difference of the weights of the columns of air is neglected, as of no consequence in practice.

Fahr. 
Fahr. for instance, it must either be brought to such standard, or a small correction will be required: but every hydrometer requires a similar adjustment of far greater magnitude. In this instrument it may in general be neglected.

In the foregoing description I have, for greater simplicity, supposed the axes of the four legs to lie all in one plane; but they may be arranged differently, and on some accounts, perhaps, with advantage*. As the liquids in pouring back from the instrument will be apt to mix, this would be prevented if a small part of the upper double end of the tubes were somewhat bent, so as to stand a little above all the tubes when they are held horizontally.

By help of an instrument of this kind very wide between the middle legs (as in fig. 2.), so as to admit of each pair being put into a separate bath, the grand question regarding the tempera-

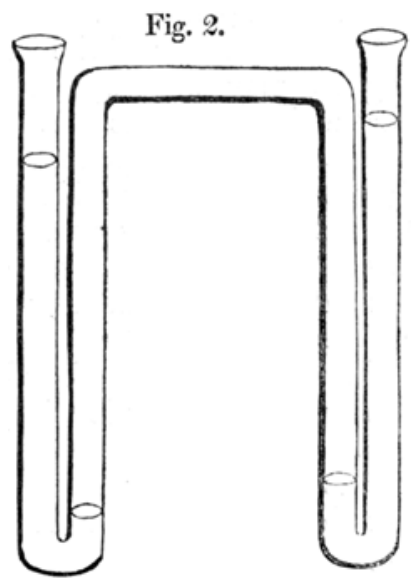
ture at which water possesses the maximum density, might be decided with greater certainty than by any other method which, so far as I know, has been employed for the purpose + . Thus if water were put into both sides, we could find at what temperature the effective column is always the shorter of the two; or, having found two temperatures at which the columns are equal, the mean between these would be very nearly the number sought. It might also be obtained by interpolating between several irregular observations lying on different sides of the maximum.

Could scales be obtained which would neither alter by moisture nor by a small change of temperature, these might be used within the baths, and the process of course would be so much the simpler. I presume, various sorts of wood, if kept dry, would undergo no change in length between $32^{\circ}$ and $50^{\circ}$; and might, therefore, be safely used as scales outside the baths. An apparatus might easily be contrived, which, being placed

* That part for instance containing the one liquid may be put on one side of a scale, and the other part on the other side of the same scale. This was the first form which I adopted. It is less liable to mix the liquids.

$\uparrow$ The method employed by MM. Dulong and Petit for determining the expansion of mercury, might, I have no doubt, be employed in solving this question; but I presume the double syphon will be more easily managed.

outside, 
outside, could measure both columns before it had time to change its temperature; but the other is surely sufficiently accurate.

Experiments of this kind, I intended to have made during the cold weather, but did not get them attended to, and the season is now too far advanced for conveniently obtaining the requisite temperatures.

The expansions of the columns or the difference in their lengths, may be increased or rendered more sensible by lengthening the tubes. But care must be taken to keep each bath at the same temperature throughout its whole depth. By placing a pretty wide tube open at both ends upright in the bath, and moving a solid piston in it, the temperature may be easily rendered uniform from top to bottom. Indeed, the motion of a piston alone, without a tube, would probably be sufficient.

The method proposed by Mr. Oswald Sym*, though quoted with approbation by Dr. Thomsont, is entirely a deception. It can at best give the temperature answering to the apparent greatest density of water in glass; just as if the water were in a bottle, and its height measured in the neck.

April 15, 1826.

Henry Meikle.

XXIV. On the magnetizing Power of the more refrangible Solar Rays. By Mrs. M. Somerville $\ddagger$.

$\mathrm{N}$ the year 1813, Professor Morichini, of Rome, discovered that steel exposed to the violet rays of the solar spectrum becomes magnetic. His experiments were repeated by Professor Configliachi, at Pavia, and also by Mons. Berard, at Montpellier, without success. I am not aware of any one having attempted them in this country, perhaps from the belief that experiments which had sometimes failed in Italy, were not likely to succeed in our more northern climate. The unusual clearness of the weather last summer, however, induced me to try what could be accomplished in this country. Accordingly, in the month of $\mathrm{July}$, an equiangular prism of flint glass, the three sides of which were each $1 \cdot 4$ by $1 \cdot 1$ inch, was fixed in a slit made to receive it in a window-shutter: by this prism a coloured spectrum was thrown on an opposite panel, at the distance of about five feet. I used for the subject of experiment a very slender sewing-needle an inch

* Annals of Philosophy, vol. ix. page 387.

+ System of Chemistry, 6th edition, vol. i. page 43.

¥ From the Philosophical Transactions for 1826 , Part I. This paper was communicated to the Royal Society, Feb. 2, 1826. 